\title{
Spor Bilimleri Alanında Öğrenci Olmak: Bir Metafor Çalışması
}

\author{
DOI: $10.26466 /$ opus. 841871
}

\author{
Senem Ceyiz * - Seray Erbil ${ }^{* *}$ - Hüseyin Can Yılmazoğlu*** \\ * Dr. Öğr. Ü., Kastamonu Üniversitesi, Spor Bilimleri Fakültesi, Kastamonu/Türkiye \\ E-Posta: ceyizsenem@hotmail.com ORCID: 0000-0002-1000-0309 \\ **Lisans Öğr., Kastamonu Üniversitesi, Spor Bilimleri Fakültesi, Kastamonu/Türkiye \\ E-Posta: seray erbil@hotmail.com ORCID: 0000-0002-2186-7119 \\ *** Lisans Öğr., Kastamonu Üniversitesi, Spor Bilimleri Fakültesi, Kastamonu/Türkiye \\ E-Posta: huseyincnylmazoglu@outlook.com ORCID: 0000-0002-8540-7134
}

\section{$\ddot{O} z$}

Bu araştırmanın amacı, spor bilimleri alanında lisans öğrenimi görmekte olan üniversite öğrenicilerinin, bu alanda eğ itim öğretim görmek konusundaki algılarını ürettikleri metaforlar yoluyla keşfetmektir. $B u$ amaç doğrultusunda araştırmada nitel araştırma yaklaşımlarından fenomenoloji deseni kullanılmıştır. Araştırmaya amaçl örnekleme yöntemlerinden maksimum çeşitlilik örneklemesi ile seçilen 83 üniversite öğrencisi (Kastamonu Üniversitesi, Siirt Üniversitesi, Mehmet Akif Ersoy Üniversitesi ve Karamanoğlu Mehmetbey Üniversitesi) katılmıştır. Verilerin toplanması aşamasında araştırmacı tarafından oluşturulan kişisel bilgi formu ve yarı yapılandırılmış formlar kullanılmıştır. Verilerin analizinde; içerik analizi yöntemi kullanılmıştır. Verilerin analizi yapılırken "Spor bilimleri alanı lisans öğrencisi" kavramına yönelik, katılımciların oluşturduğu metaforlar listelenerek, kategorilere ayrılmıştır. Araştırma kapsamında elde edilen metaforlar spor bilimleri alanında lisans öğrencisi olmanın; çaba, disiplin ve yetenek gerektiren, farklı sportifbranşları uygulama olană̆ı bulunan, öğretici lider ve çok yönlü bireyler olmaya katkı veren bir süreç olarak algılandığına işaret etmektedir. Ayrıca katılımcıların bu süreci, değerli bir alanda keyifli eğitim öğretim süreci olarak değerlendirmelerinin yan sıra ĕğtim öğretim yetersizlikleri ve istihdam sorunlarına da vurgu yaptıkları görülmektedir.

Anahtar Kelimeler: Spor bilimleri, metafor, lisans öğrencisi. 
ISSN:2528-9527

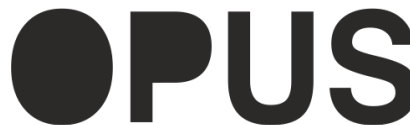

Uluslararası Toplum Araştırmaları Dergisi International Journal of Society Researches
E-ISSN : 2528-9535

YIl Year: 11

Cilt Volume: 17

Sayı Issue :38

Haziran June 2021

Makalenin Gelis Tarihi Received Date: 16/12/2020

Makalenin Kabul Tarihi Accepted Date: 03/04/2021

\title{
Being a Student in Sport Sciences: A Metaphor Study
}

\begin{abstract}
The purpose of this study was to discover the perceptions of university students studying undergraduate in sports sciences about education in this field through the metaphors they produce. For this purpose, the phenomenology pattern, as part of qualitative research approaches, was used in the research. 83 university students (Kastamonu University, Siirt University, Mehmet Akif Ersoy University and Karamanoğlu Mehmetbey University) who were selected according to maximum diversity sampling as part of purposeful sampling methods participated in the study. The personal information form and semi-structured forms developed by the researcher were used in the data collection phase. While analyzing the data, the metaphors created by the participants for the concept of "Sports sciences undergraduate student" were listed and categorized. In the analysis of the data; content analysis method was used. Metaphors obtained within the scope of the research; It indicated that being a student in the field of sports science was perceived as a process that requires effort, discipline and talent, has the opportunity to apply different sports branches, and contributes to being an instructive, leader and versatile individuals. In addition, it was seen that the participants evaluate this process as a pleasant education process in a valuable field, as well as emphasizing the problems of education and employment problems.
\end{abstract}

Keywords: Sport sciences, metaphor, undergraduate. 


\section{Giriş}

Bir bilim alanında uzmanlaşmak, lise eğitiminin devamında gelen süreçte, ilgili alanda üniversite öğrencisi olarak öğrenmeye devam etmek adına atılan adımlarla başlamaktadır. Günümüzde spor bilimleri alanı da bu uzmanlıklar arasındaki yerini almış olan bilim dallarındandır. Türkiye'de beden eğitimi ve sporun bir bilim alanı olarak kabul edilip benimsenmesinin, olgunlaşma sürecinin ve gelişim göstermesinin, birçok bilim alanında olduğu gibi çeşitli sancılarla gerçekleştiği söylenebilir. Ülkemizde 20. yüzyılda başlayan çalışmalar, “Beden Terbiyesi” eğitimi almak üzere 1909'da İsveç'e gönderilen Selim Sırrı Tarcan ve bazı Avrupa ülkelerine giden Milli Eğitim Bakanı Mustafa Necati Uğural tarafından, öncelikli olarak beden eğitimi ve sporun bir bilim dalı olduğunun kabul edilmesine yönelik olarak gerçekleştirilmiştir (Günay, 2013). Cumhuriyet döneminden itibaren daha çok öğretmen yetiştirme odaklı gerçekleştirilen beden eğitimi ve spor çalışmalarının kronolojik özeti şu şekildedir:

1927-1928 eğitim-öğretim yılında İstanbul Çapa Kız Öğretmen Okulu'nda, bir yıl süreli teorik ve pratik eğitim yapan "Jimnastik Mulallimleri Kursu-Beden Eğitimi Öğretmeni Yetiştirme Kursu" açılmıştır (Arun, 1990).

1928-1929 eğitim-öğretim yılında Millı̂ Eğitim Teşkilatınca gönderilen kabiliyetli ilkokul öğretmenlerinin katılımıyla açılan ve 3 yıllık eğitim öğretimi kapsayan ikinci kurstan 148 erkek ve 63 kadın mezun edilerek orta dereceli okullarda görevlendirilmiş ve sonrasında yeterli sayıda beden eğitimi öğretmeni yetiştirildiği düşüncesiyle kurs eğitimleri durdurulmuştur (Güven, 1996).

1932-1933 eğitim-öğretim yılında Gazi Eğitim Enstitüsü'nde üç yıllık bir eğitim öğretimi kapsayan "Beden Eğitimi Şubesi" açılmıştır (Koç, 1992). Bu bölüm geride kalan yıllar içerisinde çeşitli isim değişiklikleri sonrasında 1992 yılında Gazi Üniversitesi Beden Eğitimi ve Spor Yüksekokulu adını almıştır (Güven, 1996). 2016 yılından bu yana ise Gazi Üniversitesi Spor Bilimleri Fakültesi adı altında eğitim öğretim faaliyetlerini sürdürmektedir.

1967-1968 eğitim-öğretim yılında İstanbul Eğitim Enstitüsü'nde üç yıllık eğitim süresi olan bir beden eğitimi bölümü açılmış; yıllar içerisinde çeşitli isim değişiklikleri sonrasında, 1992 yılında Marmara Üniversitesi Beden Eğitimi ve Spor Yüksekokulu adını almıştır (Güven, 1996). 2016 yılından bu yana 
ise Marmara Üniversitesi Spor Bilimleri Fakültesi adı altında eğitim öğretim faaliyetlerini sürdürmektedir.

1970'li yıllara gelindiğinde, beden eğitimi öğretmeni yetiştirmek için açılan ve kısa bir süre içinde kapatılan eğitim öğretim kurumları da göz önünde bulundurularak, teknik elemanlar yetiştirmek amacıyla Gençlik ve Spor Bakanlığı'na bağlı dört yıllık “Spor akademileri” (Açıkada, 1992); 1974- 1975 öğretim yılında Ankara'da, "Ankara 19 Mayıs Gençlik ve Spor Akademisi", 1975- 1976 öğretim yılında da İstanbul'da "Anadoluhisarı Gençlik ve Spor Akademisi" ve Manisa'da, "Manisa Gençlik ve Spor Akademisi" olmak üzere faaliyet göstermiştir (Arun, 1990).

1977-1978 eğitim-öğretim yılında Ege Üniversitesi'nde dört yıllık eğitim ve öğretim süresi olan Beden Eğitimi ve Spor Yüksekokulu açılmıştır. Bu bölüm geride kalan yıllar içerisinde çeşitli isim değişiklikleri sonrasında, 1992 yılında Ege Üniversitesi Beden Eğitimi ve Spor Yüksekokulu ismini almıştır (Güven, 1996). 2016 yllından bu yana ise Ege Üniversitesi Spor Bilimleri Fakültesi adı altında eğitim öğretim faaliyetlerini sürdürmektedir.

1982 yılından sonra spor eğitimi veren kuruluşların, üniversitelerde birleştirilmesine karar verilmiş; 1992 yılında ise eğitim kurumlarının büyük bir çoğunluğu Beden Eğtitimi ve Spor Yüksekokulu'na dönüştürülmüştür (Aç1kada, 1997).

Günümüzde spor bilimleri alanı özel yetenek gerektiren alanlardan biri olması nedeniyle, bu alanda oğrenim görmek isteyen bireyler, ÖSYM tarafından gerçekleştirilen "Yüksek Öğretim Kurumları Sınavı" na ek olarak, hemen her üniversitenin kendi bünyesinde geçekleştirdiği uygulamalı yetenek s1navlarına da tabi tutulmaktadır. Bu sınavlarda gerekli kriterleri sağlayarak başarılı olan bireyler, spor bilimleri alanında faaliyet gösteren üniversitelerde; yüksekokullar, fakülteler ve rektörlük gibi birimlere bağlı bölümler şeklinde eğitim eğitim öğretim hizmeti veren kurumlarda öğrenim görmektedir. Türkiye'deki devlet ve vakıf üniversiteleri çatısı altında faaliyet gösteren beden eğitimi ve spor yüksekokulları ile spor bilimleri fakültelerinin son üç yıllık eğitim öğretim dönemine ait sayıları Tablo 1'de gösterildiği şekildedir. 
Tablo 1. Devlet ve Vakı Üniversitelerindeki Beden Eğitimi ve Spor Yüksekokullarn ile Spor Bilimleri Fakültelerine Ait Sayısal Veriler

\begin{tabular}{llll}
\hline $\begin{array}{l}\text { Eğitim Öğretim } \\
\text { Dönemi }\end{array}$ & $\begin{array}{l}\text { Bed.Eğt. ve Spor/Spor Bilimleri } \\
\text { ve Teknolojisi Y.O. Sayısı }\end{array}$ & $\begin{array}{l}\text { Spor Bilimleri Fakültesi } \\
\text { Sayıs }\end{array}$ & $\begin{array}{l}\text { Genel } \\
\text { Toplam }\end{array}$ \\
\hline $2016-2017$ & 70 & 26 & 96 \\
\hline $2017-2018$ & 74 & 33 & 107 \\
\hline $2018-2019$ & 77 & 41 & 118 \\
& $\left(5^{\prime}\right.$ i vakıf üniversitesi) & $\left(7^{\prime}\right.$ si vakıf üniversitesi) & \\
\hline
\end{tabular}

$\mathrm{Bu}$ verilere göre hem beden eğitimi ve spor yüksekokulları hem de spor bilimleri fakülteleri sayılarının artış gösterdiği görülmektedir.

Yine son üç eğitim öğretim yılına ait olan mevcut fakülte ve yüksekokullarda görev yapmakta olan öğretim elemanları ve dört yıllık lisans eğitimi almakta olan öğrenci sayıları Tablo 2'deki şekildedir.

Tablo 2. Beden Ĕ̆itimi ve Spor Yüksekokullan ile Spor Bilimleri Fakültelerindeki Öğrenci ve Öğretim Elemanı Sayısal Verileri (istatistik.yok.gov.tr/)

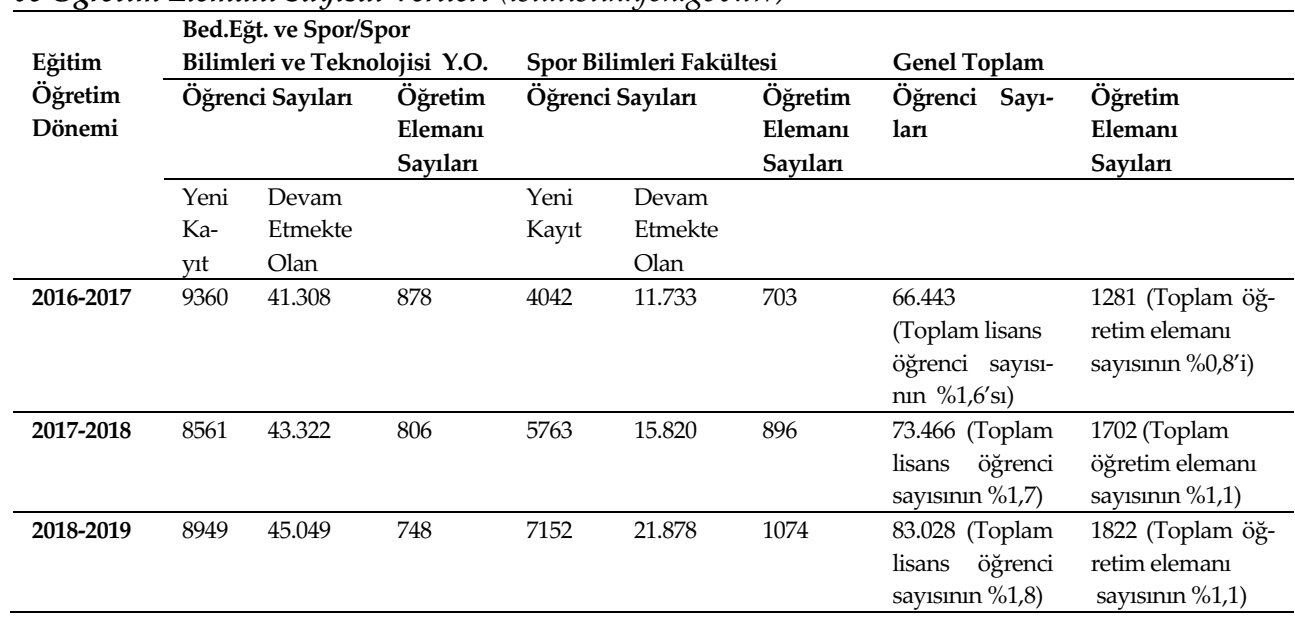

Tablo 2'deki verilere göre yüksekokul ve fakülte sayılarının artması ile orantılı olarak öğrenci sayılarının da arttı̆̆ı görülmektedir. Öğretim elemanı sayısında da artış olduğu görülse de, spor bilimleri alanında öğrenim gören öğrencilerin ülke genelindeki oranına göre aynı alanda eğitim öğretim hizmeti veren öğretim elemanı oranının yeterli olmadığı söylenebilir. Zira 1997 yılında üniversitelerin spor eğitimi veren bölüm ve yüksekokullarındaki toplam öğrenci sayısı 14.023 ve öğretim elemanı sayısı 543 iken (Açıkada, 1997), 
yirmi yılı aşkın bir sürede öğrenci sayısının yaklaşık altı katına çıtığı, öğretim elemanı sayısının ise üç kat arttığı görülmektedir.

Kısıtlı imkânlarla beden eğitimi öğretmeni yetiştirme odaklı cumhuriyet döneminden günümüze kadar gelen süreçte spor bilimleri alanının ciddi bir gelişim ve dönüşümü geride bıraktı̆̆ görülmektedir. Bu dönüşüm içerisinde spor bilimleri alanının herhangi bir bölümünde öğrenim görmekte olan öğrencilerin, eğitim öğretim süreçleri ile ilgili algılarını ortaya çıkarmak, alanın gelecekteki evrilme aşamalarına katkı sağlayacaktır. Bu çalışmada öğrencilerin algılarını ifade ederken, özgün ve kalıplardan arınmış bir çerçeve çizebilmek adına metafor kullanımı benimsenmiştir.

Metafor kelimesi Yunanca "metapherein" kelimesinden türemiş olup meta "değişmek", pherein "taşımak" anlamına gelmektedir (Levine, 2005). Metafor, bir nesnenin yönlerinin başka bir nesneye 'taşındığı' veya başka bir nesneye aktarıldığı belirli bir dilbilimsel süreç grubunu ifade eder, böylece ikinci nesne birinciymiş gibi konuşulur (Hawkes, 2017). Kesić ve Muhić (2013), spor metaforların, özlü ve mecazi bir ifade ile ulaşılan kolektif düşünce ve bilgeliğin kavşakları olarak tanımlamaktadır.

Bu tanımlar ışığında, öğrencilerin metaforik algılarından elde edilen bilgiler, spor bilimleri alanının değişim ve yenilik arayışlarına yol gösterici olabilir. Bu doğrultuda bu çalışmanın amacı, spor bilimleri alanında öğrenim görmekte olan üniversite öğrencilerinin, bu alanda öğrenci olmaya ilişkin algılarını metaforlar yolu ile açığa çıkarmaktır. Bu amaçla araştırmada aşağıdaki sorulara yanıt aranmıştır;

Spor bilimleri alanında öğrenim gören üniversite öğrencilerinin, bu alanda öğrenci olmaya ilişkin metaforik algıları nelerdir?

Elde edilen metaforlar hangi kategorilerde bir araya getirilebilir?

\section{Yöntem}

\section{Araştırmanın Amacı ve Modeli}

Araştırmada spor bilimleri alanında öğrenim gören lisans öğrencilerinin öğrencilerinin, bu alanda lisans öğrencisi olmak konusundaki algılarını metaforlar yoluyla açığa çıkarmak hedeflenmiştir. Bu amaç doğrultusunda araştırmada nitel araştırma yaklaşımlarından fenomenoloji deseni benimsenmiştir. Fenomenolojik bir çalışma, bir kavram veya fenomen hakkında, bireylerin deneyimlerinin ortak anlamın tanımlar (Creswell ve Poth, 2016). Olgular 
gündelik yaşamda olaylar, deneyimler, algılar, yönelimler, kavramlar ve durumlar gibi çeşitli biçimlerde karşımıza çıkabilmektedir (Yıldırım ve Şimşek 2013).

\section{Çalışma Grubu}

Araştırmaya 2019-2020 eğitim öğretim döneminde dört ayrı üniversitenin (Kastamonu Üniversitesi, Siirt Üniversitesi, Mehmet Akif Ersoy Üniversitesi, Karamanoğlu Mehmetbey Üniversitesi) beden eğitimi ve spor yüksekokullarında öğrenim görmekte olan 259 lisans öğrencisi katılmıştır. Katılımcılardan elde edilen veriler arasında toplam 83 katılımcının ifadeleri metaforik algı ifadesi olarak kabul edilmiş ve çalışmaya dahil edilmiştir. Spor Bilimleri alanında lisans öğrencisi olmak ile ilgili algının bu alanda öğrenim görmekte olan üniversite öğrencilerinden elde edilebileceği düşüncesiyle, araştırmanın çalışma grubu amaçlı örnekleme yöntemlerinden maksimum çeşitlilik örneklemesi ile seçilmiştir. Yaygın olasılıksız örnekleme yöntemlerinden olan amaçlı örnekleme; "amacına uygun olduğu düşünülen örneklem grubunun araştırmacı tarafından seçilmesini" ifade etmektedir ve nitel araştırmalarda kullanılmaktadır (Marshall ve Rossman, 2006). Çalışma grubundaki öğrenci çeşitliliğini maksimum derecede yansıtmak için; katılımcıların öğrenim gördükleri bölüm, sınıf düzeyleri, lisanslı sporcu olma durumları ile üniversitelerin coğrafi bölgelere göre dağılımları kriterleri göz ününde bulundurulmuştur. Veriler analiz edilirken her bir katılımcı için K1, K2, ... K83 şeklinde sayısal kodlar kullanılmıştır. Katılımcılara ait bilgiler Tablo 3 'te gösterilmiştir.

Tablo 3. Katılımcilara Ait Bilgiler

\begin{tabular}{lll}
\hline & & $\mathrm{f}$ \\
\hline Yaş & $18-22$ & 58 \\
& 23 ve üstü & 25 \\
& Bed. Ĕ̆t. Öğretmenliği & 30 \\
Bölüm & Antrenörlük Eğitimi & 22 \\
& Spor Yöneticiliği & 31 \\
& & \\
Sinuf & 1. Sinf & 14 \\
& 2. Sinff & 19 \\
& 3. Snnff & 24 \\
& 4. Sinff & 26 \\
Lisanslı sporcu & & \\
olma durumu & Evet & 53 \\
Toplam & Hayır & 30 \\
\hline
\end{tabular}




\section{Verilerin Toplanması}

Katılımcıların kendi deneyimlerinden yola çıkarak "Spor bilimleri lisans öğrencisi" ni tanımlamaları için araştırmacı tarafından oluşturulan yarı yapılandırılmış formlar kullanılmıştır. Form, "Beden Eğitimi ve Spor Yüksekokulu/Spor Bilimleri Fakültesi öğrencisi olmak ..............gibidir. Çünkü ..." şeklinde yarı yapılandırılmış iki ifadeden oluşmaktadır. Ayrıca araştırmada kullanılan form aracılığı ile, katılımcıların yaşlarına, bölümlerine, sinıflarına ve lisanslı sporcu olup olmadıklarına dair bilgiler de elde edilmiştir (Tablo 3). Formda yer alan cümlede kullanılan "gibi" kelimesi katılımcıların metaforları oluşturmaları için, "çünkü" kelimesi ise metaforları gerekçelendirmeleri için kullanılmıştır.

\section{Verilerin Analizi}

Verilerin analizinde; elde edilen verileri açıklayacak kavram ve ilişkilere ulaşmayı amaçlayan, içerik analizi yöntemi (Yıldırım ve Şimşek, 2013) kullanılmıştır. Verilerin analizi yapılırken "Spor bilimleri lisans öğrencisi" kavramına yönelik katılımcıların oluşturduğu metaforlar listenerek, ilgili kavramlarla ilişkilendirilemeyen metaforlar çalışmadan çıkarılmıştır. Bir sonraki aşamada, geriye kalan metaforlar, ortak özelliklerine göre sınıflandırılarak kodlara dönüştürülmüş; elde edilen kodlar ise kategorilendirilmiştir. Verilerden elde edilen kodlar ve bu kodlarla ilişkilendirilen kategoriler, araştırmacı tarafından yorumlanarak, bulgular açıklanmış ve anlamlandırılmıştır. Bulgular arasında neden-sonuç ilişkisi kurularak sonuçların önemine ilişkin açıklamalara yer verilmiştir.

Nitel çalışmaların geçerlik ve güvenirliğinin sağlanması için ileri sürülen yaklaşımlar "trusthworhtiness" "inandırıcllık" kavramı üzerinde yoğunlaşmış olup; "inanılırlık", "aktarılabilirlik", "güvenilebilirlik", "onaylanabilirlik" başlıkları altında incelenmektedir (Lincoln ve Guba, 1985). İnanılırlığın artırılmasına yönelik yöntemlerden olan uzman incelemesi, araştırmanın içeriği ve nitel araştırmalar konusunda uzman kişiler tarafından araştırmanın farklı boyutlarıyla incelenmesidir (Creswell, 2013). Araştırma kapsamında, spor bilimleri ve nitel araştırmalar alanında uzman 3 öğretim üyesinin görüşlerine başvurularak; araştırmanın deseni, elde edilen veriler, verilerin analizi ve sonuçların aktarılması süreçlerinde geri bildirim alınmıştır. 


\section{Bulgular}

\section{Spor Bilimleri Alanında Lisans Öğrencisi Olmaya İlişkin Metaforik Algılar}

"Spor bilimleri alanında lisans öğrencisi olmak" ile ilgili metaforlardan oluşturulan kategoriler, katılımcların ifade ettiği metaforların sayısı, metaforların kaç katılımcı tarafından oluşturulduğu ve yüzdelikleri Tablo 4'te gösterildiği şekildedir.

Tablo 4. Kategoriler, Metaforlar Ve Katılımcıların Dă̆ılımı

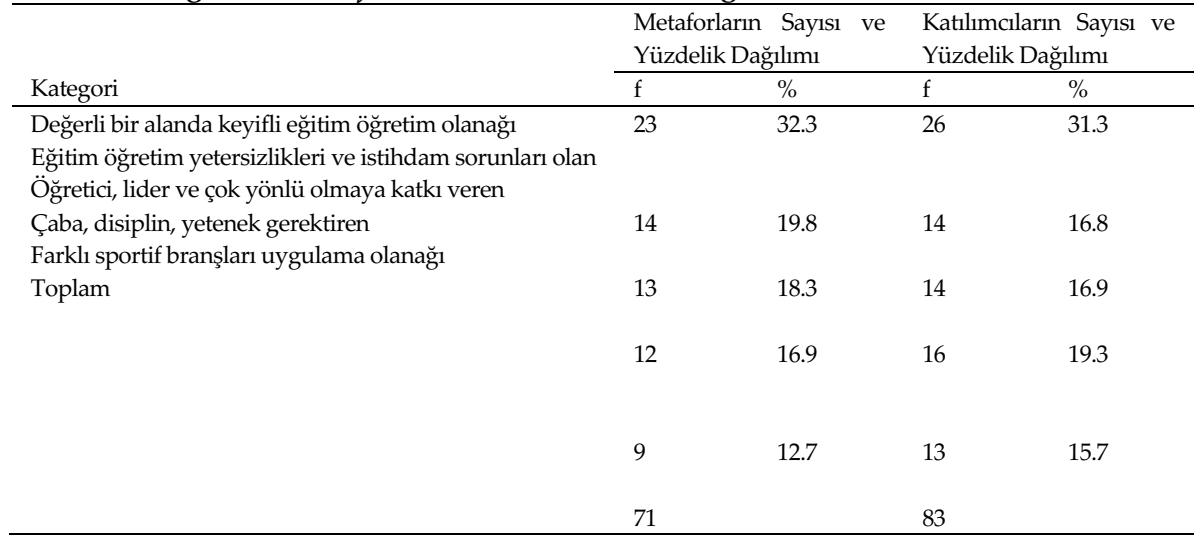

"Spor bilimleri alanında lisans öğrencisi olmak" ile ilgili metaforlar incelendiğinde, toplam 71 metafor arasında en fazla sayıda metaforun "Değerli bir alanda keyifli eğitim öğretim olanağı" kategorisi altında toplandığı görülmüş̧ür. Metaforların kullanım sıklığına göre ikinci sırayı "Eğitim öğretim yetersizlikleri ve istihdam sorunları olan" kategorisinin almış olması da çarpıcı bir veri olarak karşımıza çıkmaktadır. Katılımclardan elde edilen ilgili metaforların tamamı Tablo 5'te gösterildiği şekildedir.

Tablo 5. Spor Bilimleri Alanı Lisans Öğrencisi Olmaya İlişkin Algıları Yansıtan Metaforlar ve Metaforlarn Kullanım Sıkliklarn

\begin{tabular}{|c|c|c|c|c|c|}
\hline Kategori & Metaforlar & $\mathrm{F}$ & Kategori & Metaforlar & $\mathrm{F}$ \\
\hline \multirow{5}{*}{$\begin{array}{l}\text { Çaba, disiplin, } \\
\text { yetenek }\end{array}$} & Şarkı söylemek & 5 & & Eğlenceli bir aktivite & 3 \\
\hline & Engebeli yol & 1 & & Rüya & 2 \\
\hline & Problem cümlesi & 1 & & Gümüş & 1 \\
\hline & Sanatçı olmak & 1 & & Hayallere açılan kapı & 1 \\
\hline & Yemek yapmak & 1 & & Onurlu bir iş & 1 \\
\hline
\end{tabular}




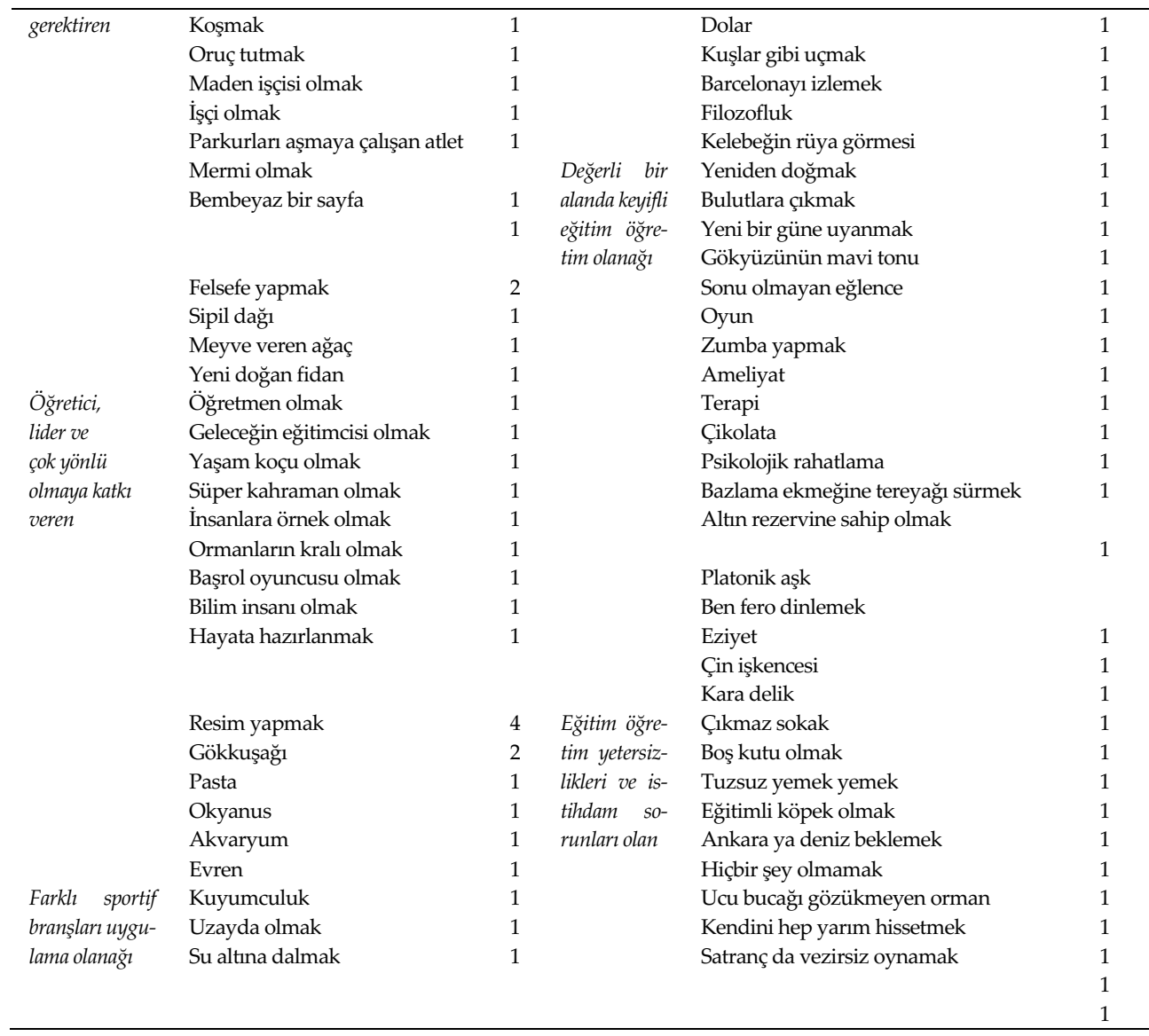

\section{Tartışma ve Sonuç}

Bu çalışmada, spor bilimleri alanında öğrenim görmekte olan lisans öğrencilerinin, bu alanda öğrenim görmenin kendileri için ne ifade ettiğine yönelik algıları metaforlar yoluyla betimlenmiştir. Katılımcıların metaforik algılarını açığa çıkarmak adına yapılan bu çalışmanın çıkış noktası, spor bilimleri alanını diğer alanlardan ayıran özellikleri öğrenci bakış açısı ile ortaya koymaktır. Katılımcıların spor bilimleri alanında öğrenci olmak ile ilgili kullandıkları metaforlar, "Çaba, disiplin, yetenek gerektiren", “Öğretici, lider ve çok yönlü olmaya katkı veren”, "Farklı sportif branşları uygulama olană̆ı", “Değerli bir alanda keyifli eğitim öğretim olanağı" ve "Eğitim öğretim yetersizlikleri ve istihdam sorunları olan" kategorileri altında toplanmıştır. Katılımcılardan 
elde edilen metaforların büyük bir kısmı, spor bilimleri alanının değerli bir alan olduğuna ve bu alanda öğrenim görmenin keyifli olduğuna işaret etmektedir. Ortaokul öğrencilerinin beden eğitimi dersine ilişkin metaforik algıları (Namlı, Temel, ve Güllü, 2017) ile benzer bir bulgu niteliğinde olan bu bulgunun spor bilimleri alanına özgü bir durum olduğu söylenebilir.

Katılımcıların spor bilimleri alanını, farklı sportif branşları uygulama olanağı bulunan bir alan olarak betimlemeleri, alanın spesifik özellikleri arasında gösterilebilir. Benzer şekilde katılımcıların öğrenim gördükleri alanın kendilerine; çok yönlü bireyler olmak ve lider özelliklerinin gelişmesine katkı vermek gibi kazanımlar sağladığı algısı da spor bilimleri alanına özgü olarak kabul edilebilir. Spor bilimleri alanında öğrenim görmekte olan bireylerin bir çoğu okula giriş sınavlarına hazırlık aşamasında, tamamı ise eğitim öğretim süresince öğrenim gördükleri bölümlerin ders kataloglarına göre farklı şekillerde, çeşitli sportif branşlarda uygulamalar yapmaktadır. Bu uygulamaların bireyleri, sporun aktif katılımcısı olarak muhafaza ettiği, diğer taraftan da bireylerin çok yönlü gelişimleri konusunda farkındalık oluşturmalarına katkı sağladığı söylenebilir. Ayrıca alan derslerinde sportif bir branşın ya da içeriğin nasıl öğretileceğine yönelik gerçekleştirilen eğitim ve öğretimin, bireylerin liderlik özelliklerinin gelişimine katkı sağladığı da söylenebilir. Alanyazında yer alan, üniversitede spor eğitimi alan öğrencilerin liderlik özelliklerinin iyi derecede olduğunu ortaya koyan araştırma (Çetinkaya ve İmamoğlu, 2018), bunu doğrular nitelikteki çalışmalardandır.

Katılımcıların bir kısmının spor bilimleri alanını; çaba, disiplin, yetenek gerektiren bir alan olarak betimlediği görülmektedir. Bireyler spor bilimleri alanında lisans öğrenimi görmek için hem mental hem de fiziksel olarak iki aşamalı bir hazırlık süreci geçirmektedirler. Bu süreç aktif sporcu olan ve olmayan bireyler açısında avantaj ve dezavantajları beraberinde getirmektedir. Gerek hazırlık sürecinde gerekse öğrencilik süresince bireyler aktif sporculuk yaşamları ile birlikte, uygulamalı ve teorik derslerden oluşan öğrenim sürecini bir arada yürütebilmek için ciddi bir çaba göstermek durumunda kalmaktadır.

Eğitim öğretim yetersizlikleri ve istihdam sorunlarına yönelik betimlemelerin de, katılımcılar tarafından alanın olumsuzlukları olarak aktarıldığı görülmektedir. Alanyazın incelendiğinde spor bilimleri öğrencilerinin istihdam kaygısı ve buna bağlı olarak oluşan umutsuzluk düzeyleri ile ilgili çalışmala- 
rın yer aldığı görülmektedir. Kırımoğlu (2010); beden eğitimi ve spor yüksekokulu son sınıf öğrencileri ile gerçekleştirdiği çalışmasında, öğrencilerin istihdam kaygısı taşıdıklarını ortaya koymuştur. Benzer şekilde Ilgar ve Cihan (2019); spor yöneticiliği öğrencilerinin alandaki istihdam sorunları nedeniyle duygusal tükenmişlik ve gelecek kaygısı taşıdıklarını tespit etmiştir. Beden eğitimi ve spor yüksekokulu öğrencilerinin öğrenim gördükleri bölüm ile umutsuzluk düzeyleri arasındaki ilişkinin araştıııldığı çalışmada, öğrencilerin umutsuzluk düzeyinin orta düzeyde olduğu görülmektedir (Aydın, 2017). Çeşitli bölümlerde öğrenim görmekte olan üniversite öğrencileri arasında (Hemşirelik, ebelik, psikolojik danışmanlık ve rehberlik, ilköğretim öğretmenliği, matematik öğr., sinff öğr., Türkçe öğr., fen bilgisi öğr., sosyal bilgiler öğr., okul öncesi öğr., bilgisayar ve öğretim teknolojileri öğretmenliği) iş bulmaya ilişkin umutsuzluk düzeyi en yüksek olan bölümün beden eğitimi ve spor öğretmenliği bölümü olduğu ortaya çıarılan sonuçlar arasındadır (Üstün vd., 2014). Spor bilimleri alanında lisans öğrenimi görmekte olan öğrenci sayı ve oranının her yıl artış gösterdiği göz önünde bulundurulduğunda (istatistik.yok.gov.tr/), her yıl mezun sayısı ve oranının arttı̆̆ı da söylenebilir. Kamu çalışanı olarak sınırlı sayıda istihdam olanağı sağlanan mezunların, kamu dışındaki istihdam alanlarında; gelir eşitsizliği, iş güvenliği noksanlıkları, uzun çalışma saatleri gibi olumsuzluklara maruz kaldıkları bir gerçektir. Nitekim öğrencilerin bir çoğu, pedagojik formasyon alarak öğretmen adayı olmak, çeşitli antrenörlük ve uzmanlık kurslarına katılarak çalıştırıc belgeleri almak gibi çabalarla alandaki istihdam alternetiflerini artırma eğilimi içerisinde olmaktadırlar. Bu durumun, bireylerin spor bilimlerinin herhangi bir alanında uzmanlaşmasının önünde bir engel olarak durduğu söylenebilir. Öğrenci ve mezun sayısının artırılmasından ziyade; yetkin, donanımlı ve alanında uzman mezunların yetiştirilmesine olanak sağlayacak bir yapılanmaya gidilmesi gerektiği düşünülmektedir. Ortaya çıkan bu durumu destekler nitelikte; beden eğtimi ve spor öğretmenliği lisans programının değerlendirildiği araştırmada; uygulamalı derslerin yetersiz olduğu, meslek bilgisi derslerinin beden eiğtimi alanına uyarlanamadığı belirtilmiştir (Namlı ve Temel, 2019). Ayrıca geçmişten günümüze beden eğitimi öğretmeni imgesinin olumsuz bir dönüşüme uğradığı görülmektedir (Sağın, 2018). Üniversite mezunu bireyler konusundaki eğitim politikalarının, niceliği başarı saymaktan ziyade niteliğe yönlenerek yeniden şekillendirilmesi gerektiği rahatlıkla söylenebilir. 
Araştırmada elde edilen metaforik algılar katılımcıların; spor bilimleri alanın "Disiplin ve çaba gerektiren", "Değerli" bir alan, bu alanda öğrenci olmayı ise "Çok yönlü ve lider" olabilme fırsatı başlıkları altında değerlendirdiklerine işaret etmektedir. Ayrıca katılımcılar "Eğitim öğretim/istihdam yetersizlikleri"ne de dikkat çekmektedir. Çalışmada elde edilen bulguların, spor bilimleri alanının gelecekteki evrilme basamaklarına katkıda bulunacağ öngörülmektedir.

Gelecekteki araştırmalar, spor bilimleri alanının eğitim öğretim faaliyetlerini gerçekleştiren öğretim elemanları ile farklı yöntemler kullanılarak yapılabilir; bu da bulgular arası örtüşme ve entegrasyon sağlayabilir. 


\title{
EXTENDED ABSTRACT
}

\section{Being a Student in Sport Sciences: A Metaphor Study}

\author{
Senem Çeyiz - Seray Erbil - Hüseyin Can Yılmazoğlu \\ Kastamonu University
}

Sports sciences are currently one of the disciplines included in this specialization. It can be argued that, as with other disciplines, the acceptance and adoption of physical exercise and sports as one of the fields of sciences in Turkey came into existence as a result of various challenges. Because sports sciences are thought to be one of the fields that require flair, individuals who wish to pursue an education in this field must pass applied ability tests at the relevant university in addition to the "Higher Education Tests" administered by the Student Selection and Placement Centre (OSYM). Individuals who have proven to be successful in such tests are instructed at universities, academies, faculties, and departments affiliated with the rectorate that offer sports sciences after meeting the stipulated criteria.

It is clear that sports science has evolved developmental and transformative processes beginning with the republican era, which focused on raising physical education teachers with limited resources, and continuing to the present. During this transformation process, revealing the educational perceptions of students enrolled in any sports sciences department will help to shape the future of this particular field of specialization. In this study, metaphors were used to create a specific and template-free framework for students to express their perceptions. The term "metaphor" is derived from the Greek word "metapherein," where "meta" means "change" and "pherein" means "carry" (Levine, 2005). Metaphor refers to linguistic processes in which one object is "carried" or "transmitted" to another, and the second object is narrated as if it were the first (Hawkes, 2017). Kesić ve Muhić (2013), define the sports metaphors as the fundamentals of the collective thoughts and wisdom attained through concise and metaphoric expressions.

In light of the aforementioned definitions, the information gleaned from the students' metaphoric perceptions may pave the way for the pursuit of 
change and innovation in the field of sports sciences. In this regard, the purpose of this study is to reveal the perceptions of university students at the departments of sports sciences for what appears to be a student in this field using metaphors. Efforts have been made to answer the following questions for this specific purpose:

What are the metaphorical perceptions of the students of the departments of sports sciences for what appears to be student in this relevant field?

How can the metaphors thus employed be classified?

The phenomenology pattern, which is one of the qualitative research methods used in this study, was chosen for this purpose. The phenomenologist study refers to the collective experience-based descriptions made by individuals for any concept or phenomenon (Creswell and Poth, 2016). Such phenomena can be encountered in a variety of ways, including everyday events, experiences, perceptions, tendencies, concepts, and cases (Yıldırım and Şimşek, 2013).

This study included 259 graduate students from four different universities' physical education and sports academies (Kastamonu University, Siirt University, Mehmet Akif Ersoy University, and Karamanoğlu Mehmetbey University). The expressions of 83 participants were deemed metaphorical and included in this study based on the data collected from the participants. Given that any perception of being a graduate student in the field of sports sciences could only be obtained from students currently enrolled in this program, maximum variation sampling method was chosen as the study group's sampling method. Sampling for the purpose of the prevalent non-probability sampling entails selecting the sampling group that best fits the researcher's purpose (Marshall and Rossman, 2006). To reflect the diversity of the students included in the study to the greatest extent possible, criteria such as the departments in which the participants attend, classes, the availability of any license, and the geographical distribution of the universities are taken into account.

Based on the experiences of the participants, semi-structured forms provided by the researcher were used to define the "Graduate Sports Science Students." The form includes two semi structured phrases such as "Being a student of the physical education and sports academy / Faculty of sports sciences is like It is because

." Furthermore, data collected 
through forms to determine the participants' age, department, class, and availability of any license. Content Analysis Method has been used to attain to the concepts and relations to clarify the data in the analysis of such data (Y1ldırım and Şimşek, 2013). When analyzing the data, the metaphors created by the participants for what it is like to be a graduate of sports sciences were listed and metaphors that did not relate to the relevant concept were omitted. In the following step, the remaining metaphors were classified and coded based on their common features, while such codes were also classified. The researcher interpreted the resulting codes of such data, as well as the categories associated with the codes, with clarified findings and meanings.

The starting point of this study which is being conducted to reveal the metaphorical perceptions of the participants, is to highlight the distinctive features of sports sciences in comparison to other fields of study in students' perceptions. The metaphors expressed by participants for being a student in the field of sports sciences are classified as follows: "Something which require effort, discipline and ability", "Contribute to the didactic quality, leadership and versatility", "Opportunity to apply different sports branches", "Joyous education in a precious field of study" and "Department with educational inadequacies and employment challenges". The majority of the metaphors used by the participants emphasize the fact that sports sciences is a valuable field of study and that taking a course in this field of study is enjoyable.

\section{Kaynakça / References}

Açıkada, C. (1992). Beden eğitimi ve spor öğretmeni yetiştirmede müfredat programı sorunları. Spor Bilimleri Dergisi, 3(4), 3-13.

Açıkada, C. (1997). Türkiye'de spor eğitimi veren kurumlarin yeniden yapılanması ve hakemli çalışmaların gelişimi. Spor Bilimleri Dergisi, 8(1), 17-42.

Arun, A. C. (1990). Türkiye'de Cumhuriyet devrinde beden eğitimi öğretmeni yetiştirme çalışmaları ve aşamaları. Journal of Physical Education and Sports Studies, 1(1), 9-13.

Aydın, E. (2017). Besyo öğrencilerinin öğrenim gördükleri bölüm ile umutsuzluk düzeyleri arasındaki ilişki. Journal of International Social Research, 10(49), 263-267. doi: 10.17719 /jisr.2017.1577

Creswell, J. W. (2013). Araştırma Deseni: Nitel, Nicel ve Karma Yöntem Yaklaşımları. [S.B. Demir (Ed.), G. Haciömeroğlu, (Çev.)]. Ankara: Eğiten Kitap. 
Creswell, J. W. ve Poth, C. N. (2016). Qualitative inquiry and research design: Choosing among five approaches. Sage publications. https://tinyurl.com/y2gkmkma adresinden erişildi.

Çetinkaya, G. ve İmamoğlu, G. (2018). Üniversite spor eğitimli öğrencilerin liderlik yönelimlerinin farkli değişkenlere göre araştrılması. Journal of International Social Research, 11(59), 719-725. doi: 10.17719/jisr.2018.2681

Günay, N. (2013). Atatürk döneminde Türkiye'de beden eğitiminin gelişimi ve Gazi Beden Terbiyesi Bölümü. Atatürk Araştırma Merkezi Dergisi, 29(85), 72-100.

Güven, Ö. (1996). Türkiye'de Cumhuriyet döneminde beden eğitimi ve spor öğretmeni yetiştiren okulların eğitimini hazırlayıı çalışmalar. Gazi Beden Eğitimi ve Spor Bilimleri Dergisi, 1(2), 70-82.

Hawkes, T. (2017). Metaphor (Vol. 24). Taylor \& Francis.

Ilgar, E. A. ve Cihan, B. B. (2019). Spor yöneticiliği programlarında öğrenim gören öğrencilerin sektörel beklenti, mesleki belirsizlik ve gelecek kaygilarının incelenmesi: fenomonolojik bir çözümleme. Spor Eŏitim Dergisi, 3(1), 81-92.

Kesić, D. ve Muhić, E. (2013). Sports in metaphor and metaphor in sports. Sport Logia, 9(1), 28-33. doi: 10.5550/sgia.130901.en.004K

Kırımoğlu, H. (2010). Türkiye'deki beden eğitimi ve spor yüksekokulu son sınıf öğrencilerinin istihdam sorunu açısından umutsuzluk düzeylerinin incelenmesi. Kastamonu Ĕ̈itim Dergisi. 18(1), 37-46.

Koç, Ş. (1992). Neden spor bilimleri fakültesi? Beden Eğitimi ve Spor Araştırmalar Dergisi, 3(9), 11-16.

Levine, P. M. (2005). Metaphors and images of classrooms. Kappa Delta Pi Record, 41(4), 172-175. doi: 10.1080/00228958.2005.10532066

Lincoln, Y. S. ve Guba E. G. (1985). Naturalistic İnquiry (Vol. 75). Sage. https://tinyurl.com/y3jm79so adresinden erişildi.

Marshall, C. ve Rossman, G.B. (2006). Designing Qualitative Research. London: Sage

Naml, A. K. ve Temel, C. (2019). Beden eğitimi ve spor öğretmenliği lisans programinin değerlendirilmesi ve program önerisi. Milli Eğitim Dergisi, 48(1), 321-351.

Namll, A., Temel, C., \& Güllü, M. (2017). Ortaokul öğrencilerinin beden eğitimi dersine ilişkin ürettikleri metaforlar. Kastamonu Ĕ̆itim Dergisi, 25(2), 479-496.

Sağın, A. E. (2018). Öğretmen dönüşümü özelinde beden eğitimi öğretmenliği: Nereden? nereye? (Master's thesis, İnönü Üniversitesi Sağllk Bilimleri Enstitüsü).

Üstün, G., Dedekoç, Ş., Kavalall, T., Öztürk, F., Sapcl, Y. ve Can, S. (2014). Üniversite son sinuf öğrencilerinin iş bulmaya ilişkin umutsuzluk düzeylerinin incelenmesi. Amasya Üniversitesi Ĕ̆itim Fakültesi Dergisi, 3(2), 200-221. 
Yıldırım, A. ve Şimşek, H. (2013). Sosyal Bilimlerde Nitel Araştırma Yöntemleri (9. Baskı). Ankara: Seçkin Yayıncllk.

YÖK. (t.y). İstatikler. 28.03.2020 tarihinde erişilmiştir.

\section{Kaynakça Bilgisi / Citation Information}

Çeyiz, S., Erbil, S. ve Yılmazoğlu, H. C. (2021). Spor bilimleri alanında öğrenci olmak: bir metafor çalışması. OPUS-Uluslararası Toplum Araştırmaları Dergisi, 17(38), 5210-5227. DOI: 10.26466/opus.841871 